\title{
Effect of Soy Bean Isoflavon on Lipid Accumulation in 3T3-L1 Adipocytes
}

\author{
Teruhiko Matsushima, Noriko Yoshimura, Yuumi Koseki \\ Department of Human Life Science, Jissen Women's University, Tokyo, Japan \\ Email: matshima@nifty.com
}

Received 15 July 2015; accepted 10 September 2015; published 17 September 2015

\begin{abstract}
Several nutrition and food ingredients are supposed to have beneficial effects, but precise cell biological mechanism has not been elucidated. Among food ingredients, polyphenols such as soy bean isoflavon genistein and wine resveratrol have been reported to have effects on lipid metabolism and cardiovacular diseases (1). In order to elucidate the effect of genistein on obesity, we cultured adipocyte and observed of genisten to lipid accumulation in cells. Triglyceride accumulation was suppressed by genistein when it was added at the time of differentiation but not when added after differentiation. Genistein is considered to suppress lipid accumulation by suppressing the differtiation of adipocytes.
\end{abstract}

\section{Keywords}

\section{Obesity, Adipocyte, Genistein, Resveratrol}

\section{Introduction}

Obesity is one of world-wide problem leading to disseases including atherosclerosis. Several nutrition and food ingredients are considered to have beneficial effects [1], but precise cell biological mechanism has not been elucidated. Among food ingredients, polyphenols such as soy bean isoflavon genistein and green tea epigallocathecin gallate have been reported effects on lipid metabolism and cardiovacular diseases [2]. In this paper we studied the effects of genistein and EGCG on differentiation to adipocyte and lipid accumulation in 3T3L1 preadipocytes.

\section{Methods}

\subsection{Cell Culture}

3T3L1 preadipocytes derived from mice skin fibroblast were obtained from American Tissue Culture Collection. Cells were cultured in Dulbecco's modified essential medium (DMEM) including 10\% fetal calf serum (FCS) in atmosphere of $5 \% \mathrm{CO}_{2}$ at $37^{\circ} \mathrm{C}$. Two days after confluency, ells were differenciated to adipocyte by standard procedure [3], by adding differentiation mix at final concentration of $5 \mu \mathrm{g} / \mathrm{ml}$ insulin, $1.0 \mu \mathrm{M}$ dexamethazone and $400 \mu \mathrm{M}$ isobutyl methyl xanthine. Afer 2 days, the medium was changed to DMEM ontaining $0.1 \mathrm{mg} / \mathrm{ml}$ 
insulin and 10\% FCS and the culture was continued.

\subsection{Experiments}

Genistein, epigallocatech ingallate (EGCG) and $\beta$-estradiol was purchased from Sigma. Genisteinn and $\beta$-estradiol was dissolved in dimethylsulfoxide and EGCG was dissolved in water. In experiment A, testing materials were added to the cells simultaneously at the time of differentiation and lipid accumulated in cells was extracted and triglyceride was quantified at 3, 5, 7 and 10 days. In experiment B, testing materials were added seven days after differentiation and triglyceride was quantified at 5, 10, 15 and 21 days.

\subsection{Lipid Staining}

Cells on culture dishes were washed twice with phosphate buffered saline (PBS), fixed with $10 \%$ formalin for $10 \mathrm{~min}$, soaked in $60 \%$ isopropanol for one minute and staind with fleshly prepared $1.8 \%$ Oil-Red O stain solution in $60 \%$ isopropanol for one hour. Cells were washed with $60 \%$ isopropanol and then tap water, and stained with hematoxylin solution for $10 \mathrm{~min}$. After washing the cells with tap water, the cells were observed by microscope.

\subsection{Lipid Extraction and Quantification}

Cells on dishes were washed twice by PBS, scraped off in $25 \mathrm{mM}$ Tris-HCl 1mM Ethylenediaminetetraacetic acid pH7.4 and disrupted by sonication in ice-water for $10 \mathrm{~min}$. Lipid was extracted from cell lysate by equal volume of 1:1 chloroform-methanol. After adding $20 \mathrm{ml}$ of Triton X100-methanol (1:1) the organic solvent was browed out by nitrogen gas flow and the solution was diluted by $220 \mu \mathrm{l}$ water. Triglyceride concentration was quantified by enzymatic method using Triglyceride E-test (Wako).

\section{Results}

After differentiation, cells gradually accumulated lipid and lipid droplets became visible around the third or the forth days. In experiment A (Figure 1), where the reagents were added to cells at the timing of differentiation, cellular triglyceride accumulation was suppressed to $26.3 \%$ of control by genistein and to $78.8 \%$ by EGCG and $43.2 \%$ by $\beta$-estradiol respectively. At the $10^{\text {th }}$ days, further accumulation of lipid was observed but it was also suppressed to $17.8 \%$ by genistein and to $54.8 \%$ by EGCG and $41.0 \%$ by $\beta$-estradiol. On the other hand, in experiment B (Figure 2), where the reagents were added 7 days after differentiation, no difference was observed in triglriceride accumulation at any point of time course.

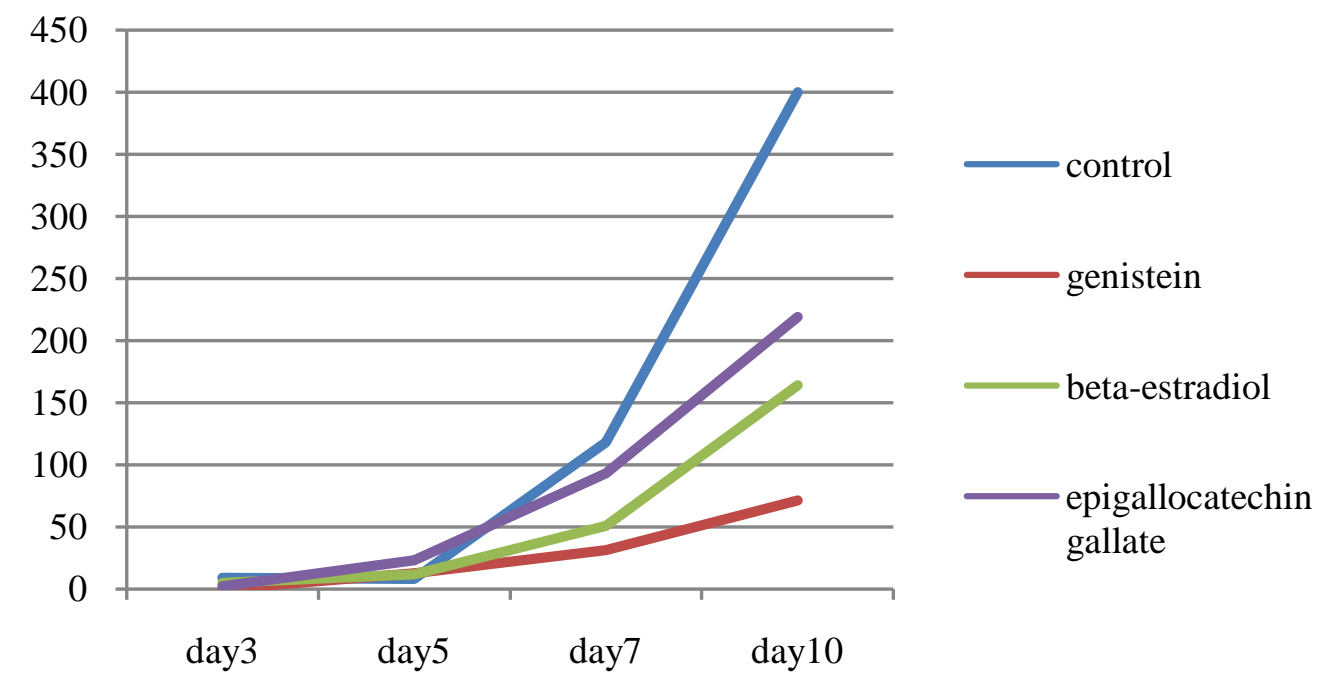

Figure 1. Time course of triglyceride content in 3T3L1 cells. Reagents were added at the timing of cell differentiation. 


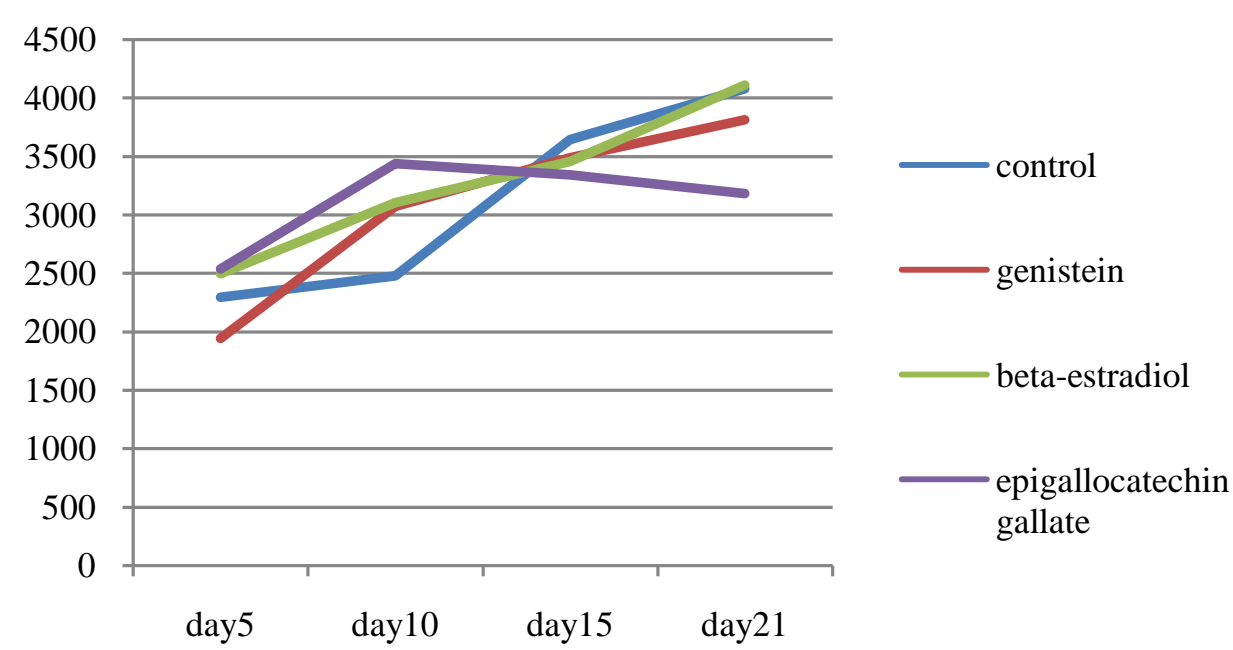

Figure 2. Time course of triglyceride content in 3T3L1 cells. Reagents were added 7days after differentiation.

\section{Discussion}

Soy isoflavon was reported to increase lypolysis and oxidation in 3T3L1 when adminstered together with Lcarnitine [3]. It was also confirmed in mice that isoflavone increase energy expenditure and decrease adiposity [4]. In this study, we found that genistein, soy bean isoflavone, suppresses triglyceride accumulation in 3T3L1 cells when it was added at the time of differenciation but not when added later. It suggests that after differentiation, genistein has no effect on lipid accumulation, suggesting that genistein may have influence on adipocyte differentiation. Further studies on differentiation, such as about transcriptional factor PPAR-g or CEBP are necessary.

\section{Acknowledgements}

This study was supported by Grant-for-Aide No. 24650503 from the Ministry of Education and Science, Japan.

\section{References}

[1] Moriguchi, E.H., Moriguchi, Y. and Yamori, Y. (2004) Impact of Diet on the Cardiovascular Risk Profile of Japanese Immigrants Living in Brazil: Contributions of World Health Organization CARDIAC and MONALISA Studies. Clinical and Experimental Pharmacology and Physiology, 31, S5-S7. http://dx.doi.org/10.1111/j.1440-1681.2004.04119.x

[2] Anderson, J.W., Smith, B.M. and Washnock, C.S. (1999) Cardiovascular and Renal Benefits of Dry Bean and Soybean Intake. The American Journal of Clinical Nutrition, 70, 464S-474S.

[3] Murosaki, S., Lee, T.R., Muroyama, K., Shin, E.S., Cho, S.Y., Yamamoto, Y. and Lee, S.J. (2007) A Combination of Caffeine, Soy Isoflavones, and L-Carnitine Enhances both Lipolysis and Fatty Acid Oxidation in 3T3-L1 and HepG2 Cells in Vitro and in KK Mice in Vivo. Journal of Nutrition, 137, 2252-2257.

[4] Cederroth, C.R., Vinciguerra, M., Kühne, F., Madani, R., Doerge, D.R., Visser, T.J., Foti, M., Rohner-Jeanrenaud, F., Vassalli, J.D. and Nef, S. (2007) A Phytoestrogen-Rich Diet Increases Energy Expenditure and Decreases Adiposity in Mice. Environmental Health Perspectives, 115, 1467-1473. http://dx.doi.org/10.1289/ehp.10413 